\title{
Is solid state lighting ready for the incandescent lamp phase-out?
}

\section{Nadarajah Narendran}

Nadarajah Narendran, "Is solid state lighting ready for the incandescent lamp phase-out?," Proc. SPIE 8123, Eleventh International Conference on Solid State Lighting, 812302 (22 September 2011); doi: 10.1117/12.899262

SPIE Event: SPIE Optical Engineering + Applications, 2011, San Diego, California, United States 


\title{
Is solid-state lighting ready for the incandescent lamp phase-out?
}

\author{
Nadarajah Narendran* \\ Lighting Research Center, Rensselaer Polytechnic Institute, 21 Union St., Troy, NY 12180 USA
}

\begin{abstract}
To encourage energy-efficient light sources, many governments around the globe have introduced legislation to phase out the incandescent lamp for general illumination. The United States enacted the Energy Independence and Security Act of 2007 that introduced minimum efficiency standards for lighting that will eliminate some incandescent lamps in the range of $40 \mathrm{~W}$ to $100 \mathrm{~W}$ by 2014 . This begs the question: Is solid-state lighting ready to handle the incandescent phaseout? There is no doubt today that LED technology has advanced to a stage where it can cater to many lighting applications, including A-lamp replacements up to $60 \mathrm{~W}$. However, several challenges must still be addressed before white LED based A-lamp replacements are adopted broadly in the general lighting market. The LED lighting community is actively seeking answers to many of the technical and market challenges. This paper discusses the current state of LED lighting technology, where it is in terms of performance, the challenges to be overcome, and the considerations needed if LED lighting is to succeed in the market for incandescent replacement lamps.
\end{abstract}

Keywords: LED, light-emitting diode, solid-state lighting, incandescent, regulation, performance, energy, replacement

\section{INTRODUCTION}

Four years ago, the United States enacted the Energy Independence and Security Act of 2007, which introduced minimum efficiency standards for lighting. Since early in 2011, the general public has received a barrage of publicitysome accurate, some inaccurate - about what will happen to the most common household light bulbs starting on January 1, 2012. In the past year, there have been anecdotal reports of incandescent lamp hoarding, in which people have been stockpiling light bulbs for the future. ${ }^{[1,2,3]}$ In July 2011, a vote was brought before the United States House of Representatives to pass a bill that would repeal the "light bulb ban," but the bill failed. ${ }^{[4]}$ Opinions also have been put forth about whether such legislation will or will not actually save energy.

Another type of publicity gathered steam in 2011 as well. As news spread of the incandescent lamp phase-out, a growing number of discussions occurred about what will replace Thomas Edison's classic invention when it is no longer available. Inevitably, these discussions - manifesting as reports by media, informational announcements by government, and marketing pitches by lighting manufacturers - turned to the prospects of not only compact fluorescent lamps (CFLs), but also of LED (light-emitting diode) and solid-state lighting. LED lighting has been advancing rapidly over the past decade, garnering much attention around the world as the most promising white light source for the future.

The question then becomes: Is solid-state lighting ready for the incandescent lamp phase-out? Will consumers easily be able to switch out their incandescent lamps with an LED-based replacement lamp? And will they accept the change? This paper discusses the current state of LED lighting technology, where it is in terms of performance, the challenges to be overcome, and the considerations needed if LED lighting is to succeed in the market for incandescent replacement lamps.

\section{BACKGROUND}

\subsection{Light and human vision}

Regardless of the type of light source used, light functions primarily for the people who see it because the term "light" cannot exist without the human eye. Therefore, the application of light should meet the needs (visual and non-visual) of people. Beyond this primary goal, the application and design of good lighting should integrate well with the architecture,

*narenn2@rpi.edu; www.lrc.rpi.edu/programs/solidstate

Eleventh International Conference on Solid State Lighting, edited by Matthew H. Kane, Christian Wetzel, Jian-Jang Huang, Proc. of SPIE Vol. 8123, 812302 - @ 2011 SPIE · CCC code: 0277-786X/11/\$18 · doi: 10.1117/12.899262 
enhance task performance, create a visually appealing space, be responsive to the well-being of users, and be energy efficient and environmentally low-impact. ${ }^{[5]}$

Visible light is described as the radiant energy capable of exciting the retina and producing a visual sensation in the range of $380 \mathrm{~nm}$ to $760 \mathrm{~nm} .{ }^{[5]}$ The human eye sees light because of a unique spectral response function, known as $V \lambda$, which is used as one of several measurements of light.

\subsection{Light source performance and energy demand}

Performance is key to the success of a lighting technology. The most common performance parameters used to describe a light source or lighting system include luminous flux (lumens), luminous efficacy (lumens per watt [lm/W]), color appearance (correlated color temperature [CCT] and chromaticity), color rendering (color rendering index [CRI]), life (in hours), and lumen maintenance (rate of decrease in light output over time). Light distribution may also be important to the selection of a lighting system or replacement lamp.

The chief criticism of the incandescent lamp is its very low luminous efficacy, which averages about $15 \mathrm{~lm} / \mathrm{W}$. Less than $7 \%$ of the power emitted by the incandescent lamp is in the form of visible light; the rest is radiant heat. In comparison, a CFL has an average luminous efficacy of $60 \mathrm{~lm} / \mathrm{W}$. Incandescent lamps fill a significant portion of light sockets, especially in homes and residences, which is one reason why lighting accounts for $22 \%$ of total electricity use in the United States. ${ }^{[6]}$ According to the U.S. Energy Information Agency, in 2001 lighting accounted for 101 billion kWh $(8.8 \%)$ of U.S. household electricity use. ${ }^{[7]}$ Considering the growing demand for energy around the globe, limited energy supplies, and political unrest in oil-producing regions of the world, legislation and regulation have been used in many nations to promote energy conservation and energy-efficient products.

\subsection{U.S. national and international energy legislation}

Legislation to increase the efficiency of lighting - a more correct description than "incandescent lamp phase-out" or "incandescent ban"- has passed in numerous countries. The purpose of this legislation is to encourage the production and use of light sources and lighting systems with greater efficiency, as one means of reducing overall energy usage within a country.

In the United States, the Energy Independence and Security Act of 2007 establishes minimum efficiency standards for general service incandescent lamps and incandescent reflector lamps. For general service incandescent lamps (including modified spectrum), the act targets a power reduction of approximately $25 \%$ (Table 1 ). The phase-out portion of the legislation begins in January 2012 for $100 \mathrm{~W}$ lamps, which must produce the same amount of lumens at a maximum of $72 \mathrm{~W}$. In the year 2013, the second year of the phase-out, $75 \mathrm{~W}$ lamps will be affected. In 2014, the final year of the phase-out, $60 \mathrm{~W}$ and $40 \mathrm{~W}$ lamps will be affected ${ }^{[8]} \mathrm{In}$ the state of California, the three-year schedule is shifted one year earlier, with the state's initial phase-out year having begun in January 2011. Some incandescent reflector lamps, including PAR20, PAR30, PAR38, BR30, R20, and R40 type lamps of certain wattages, also have mandated efficiency standards under the energy act.

Table 1. U.S. lighting efficiency standards for general service incandescent lamps ${ }^{[8]}$

\begin{tabular}{lllll}
\hline \multicolumn{5}{c}{ General Service Incandescent Lamps } \\
\hline Current Wattage & Lumen Range & New Maximum Wattage & Minimum Lifetime & Effective Date \\
\hline 100 & $1490-2600$ & 72 & 1000 hours & $1 / 1 / 2012$ \\
\hline 75 & $1050-1489$ & 53 & 1000 hours & $1 / 1 / 2013$ \\
\hline 60 & $750-1049$ & 43 & 1000 hours & $1 / 1 / 2014$ \\
\hline 40 & $310-749$ & 29 & 1000 hours & $1 / 1 / 2014$ \\
\hline \multicolumn{5}{c}{ Modified Spectrum General Service Incandescent Lamps } \\
\hline Current Wattage & Lumen Range & New Maximum Wattage & Minimum Lifetime & Effective Date \\
\hline 100 & $1118-1950$ & 72 & 1000 hours & $1 / 1 / 2012$ \\
\hline 75 & $758-1117$ & 53 & 1000 hours & $1 / 1 / 2013$ \\
\hline 60 & $563-787$ & 43 & 1000 hours & $1 / 1 / 2014$ \\
\hline 40 & $232-562$ & 29 & 1000 hours & $1 / 1 / 2014$ \\
\hline
\end{tabular}


After the effective dates listed, any incandescent lamp that can meet these requirements can be produced; however, research efforts to date to produce more efficient incandescent lamps have been limited to a few types of halogen-based lamps. On the market side, retailers and distributors may sell the banned products beyond the effective dates until their inventories are depleted.

An important point to remember is that not all incandescent lamps are banned. Many types of specialty incandescent lamps are not affected by the legislation, including candelabra-base lamps, 3-way light bulbs, appliance lamps, bug lights, plant grow lights, and colored lamps, to name just a few. ${ }^{[8]}$

\section{LEDS AS SOURCES FOR GENERAL ILLUMINATION}

There are many light sources on the market today that can meet the mandated requirements; however, LEDs offer a much higher energy-savings potential because their theoretical efficacy limits are much higher than those of other light sources. The promise of greater energy savings, along with the ability to produce acceptable white light color, has prompted many countries to invest in research and development programs for LEDs. Today, commercially available LEDs have an efficacy of greater than $100 \mathrm{~lm} / \mathrm{W}$ with a goal of reaching $200 \mathrm{~lm} / \mathrm{W}$ by the year 2020. ${ }^{[9]}$ To reach this goal, improvements are needed at several stages: internal quantum efficiency, "green gap" efficiency, extraction efficiency from the chip, phosphor efficiency, and extraction efficiency from the LED package. Also necessary is a decrease in cost of the LED packages used to create lighting products.

The individual LED package is just one component within a complete lighting product or system. The performance of the complete product or system, such as an LED-based replacement lamp, is what ultimately matters to the consumer or end-user. How the LED performs outside the system is not a good indicator of its performance within a system, since the design of the system, its thermal management, and its installation environment will all have an effect on light output, life, and color. Other system components have their own efficiencies as well, with optics, heat sinks, and drivers averaging $80-90 \%$ efficiency. Overall, the average efficacy of an LED lighting system is approximately $60 \%$ of the bare LED package's efficacy.

LED lighting system performance has improved steadily in the past few years. Both LED A-lamps and reflector lamps are available under the U.S. Energy Star program with system efficacies ranging from approximately 37 to $70 \mathrm{~lm} / \mathrm{W}$ (Figure 1).
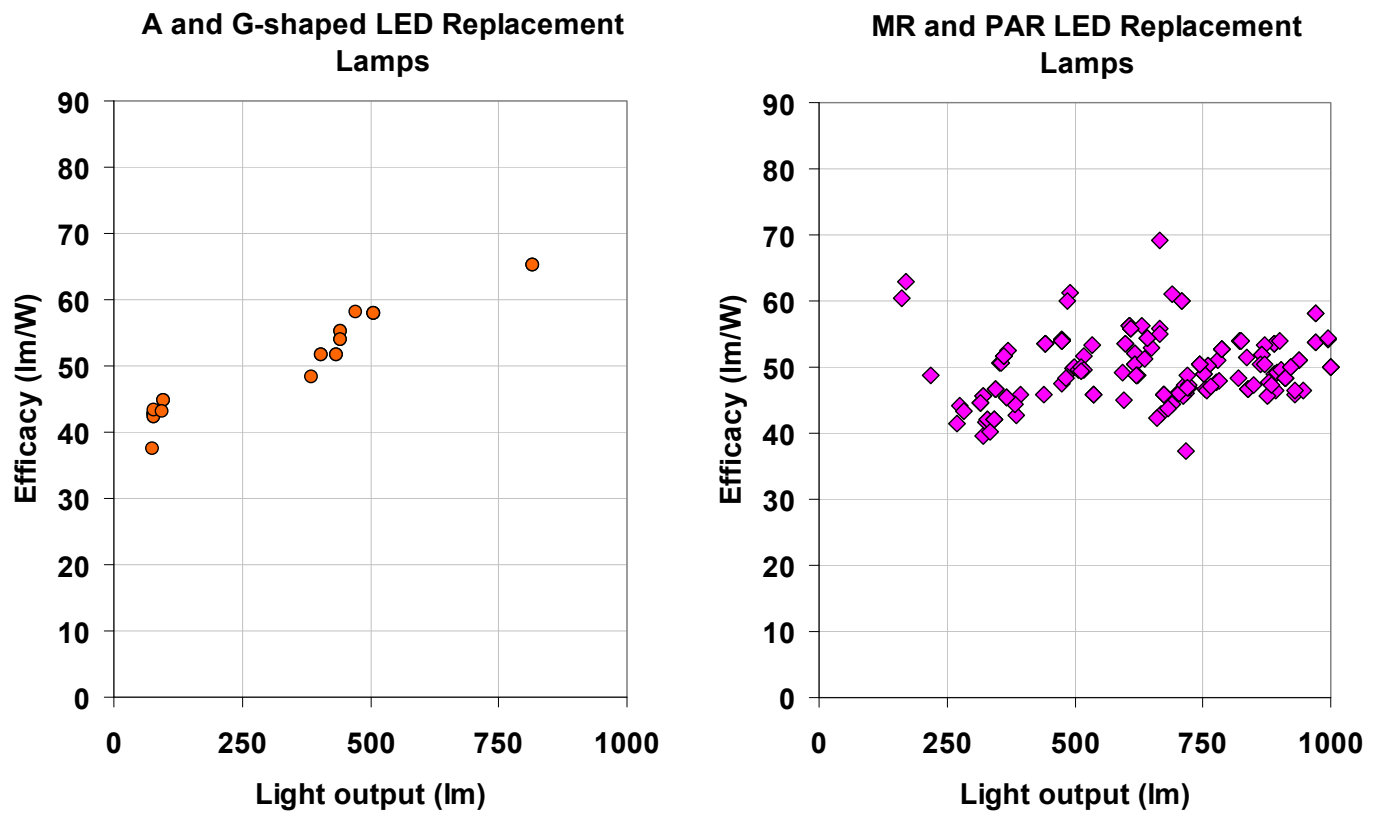

Figure 1. Plotted light output and efficacy of LED replacement lamps (A, G, MR, and PAR types) qualifying for the Energy Star program logo (based on data from the Energy Star website, August 2011) ${ }^{[10]}$ 
Designing an LED-based lighting system or replacement lamp is complex because of multiple interacting parameters (Figure 2). In nearly every case, optimizing the lighting system for a given application will involve some compromise in terms of performance or cost. This also means that one design solution cannot fit all lighting applications.

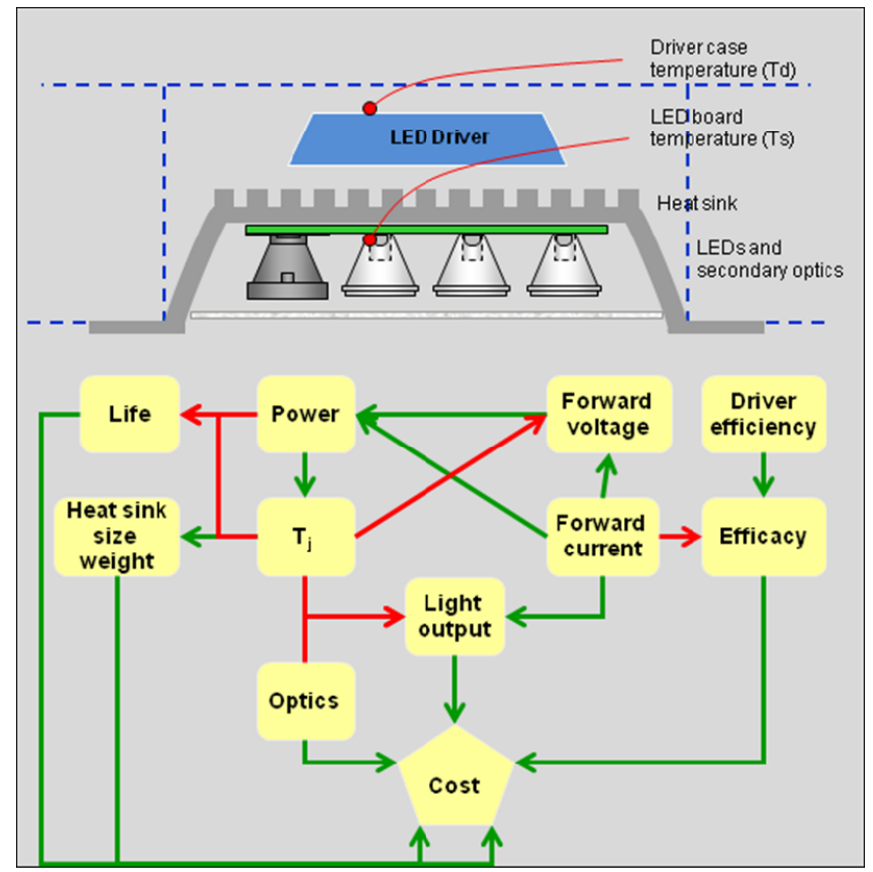

Figure 2. Simple schematic of a lighting system and decision chart for optimizing system performance ${ }^{[11]}$

The U.S. Department of Energy in 2008 launched the Bright Tomorrow Lighting Prize (L-Prize ${ }^{\mathrm{SM}}$ ) competition to spur the lighting industry's development of high performance, energy-efficient LED replacements for incandescent lamps by offering a cash prize, promotions, and other incentives. The first prize category sought replacements for a $60 \mathrm{~W}$ incandescent A-lamp and specified minimum requirements of greater than $90 \mathrm{~lm} / \mathrm{W}$ efficacy, less than $10 \mathrm{~W}$ input power, greater than $900 \mathrm{~lm}$ of flux, more than 25,000-hour life, a CRI of 90 or greater, and a CCT of 2700-3000 K. After a series of independent short-term and long-term performance testing and field evaluations, the first winner, Philips Lighting, was announced in August 2011. ${ }^{[12]}$ The next competition will seek a replacement for a PAR38 lamp.

\section{CONSIDERATIONS FOR THE BROAD ACCEPTANCE OF LED-BASED REPLACEMENT LAMPS}

To ensure the acceptance of LED-based replacement lamps, considerations need to be made for the photometric quality of the light, the mechanical design of the lamp, the electrical performance of the lamp, the system's integration and reliability, and the ease of purchase. Each of these considerations is described below.

\subsection{Photometric qualities}

Light output distribution, color rendering, color appearance, and uniformity are some of the most important photometric qualities for an LED-based replacement lamp.

Most residential luminaires were designed for the distribution given by an incandescent A-lamp or R or PAR reflector lamps, which have a wide, nearly omnidirectional distribution. For example, in a tabletop luminaire, the incandescent Alamp casts light both upward to the ceiling and down to the table beneath. Some LED-replacement lamps have a more narrow distribution, with most of the light directed upward and little reaching the table below. Consumers may find this type of distribution unacceptable in this particular application. 
In terms of light source color, general illumination requires good color-rendering properties, a CCT in the range of 2700 $\mathrm{K}$ to $5500 \mathrm{~K}$ (depending on the application), and chromaticity values close to the blackbody locus. Equally important is lamp-to-lamp color consistency. Lamps with perceptible color differences, when placed in close proximity, can be unacceptable to some users.

\subsection{Mechanical design}

The size, configuration, and weight of a replacement lamp are important considerations. If they match closely to the incandescent lamp to be replaced, they are more likely to fit in the designated luminaire. If they do not fit, they may not be accepted by the consumer. Weight generally has not been an issue for replacement lamps. Early retrofit CFLs with magnetic ballasts weighed more than the incandescent lamps they replaced, and today's LED replacement lamps also are significantly heavier due to metal heat sinks.

Another aspect of the mechanical design is thermal management. The thermal management techniques employed must be adequate to keep the LED junction temperature low enough to ensure the lamp's reliability. The junction temperature depends on the operating current as well as the environment in which the lamp is installed. Enclosed, surface mounted, and recessed luminaires often have higher ambient temperatures, leading to higher LED junction temperatures that can affect the lamp's performance and life (Figure 3).

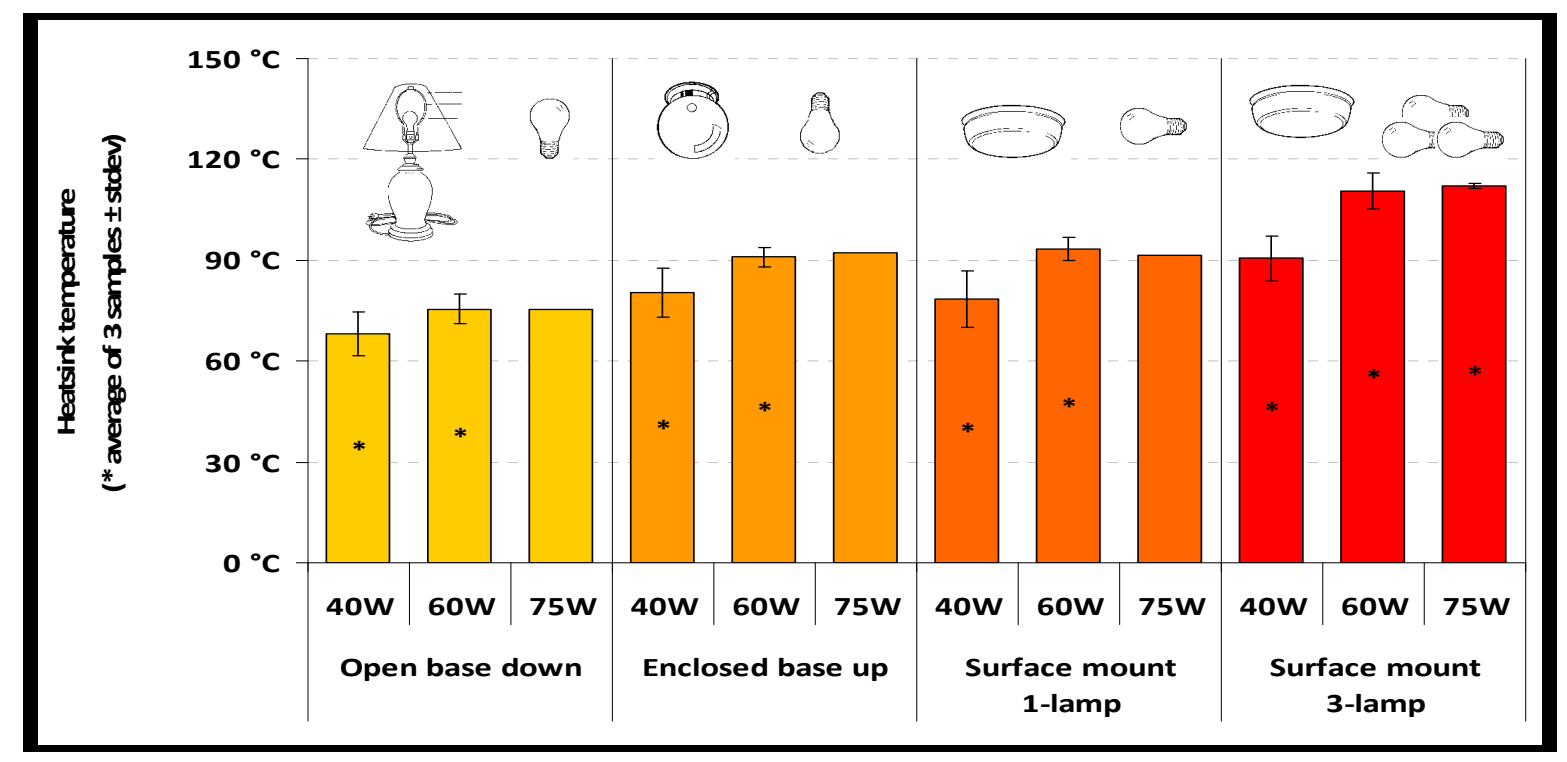

Figure 3. Heat sink temperatures of LED replacement lamps (40 W, $60 \mathrm{~W}$, and $75 \mathrm{~W}$ A-lamp equivalents) when operated within some commonly used luminaires

A 2010 study by the Lighting Research Center of LED replacement A-lamps showed high temperatures surrounding the lamps, which led to the failure of seven out of twenty-two lamps within 4,000 hours. Lumen depreciation was also high during warm-up times. A few products did show good lumen maintenance after an initial $10-15 \%$ drop in light output (Figure 4). ${ }^{[1]}$ 


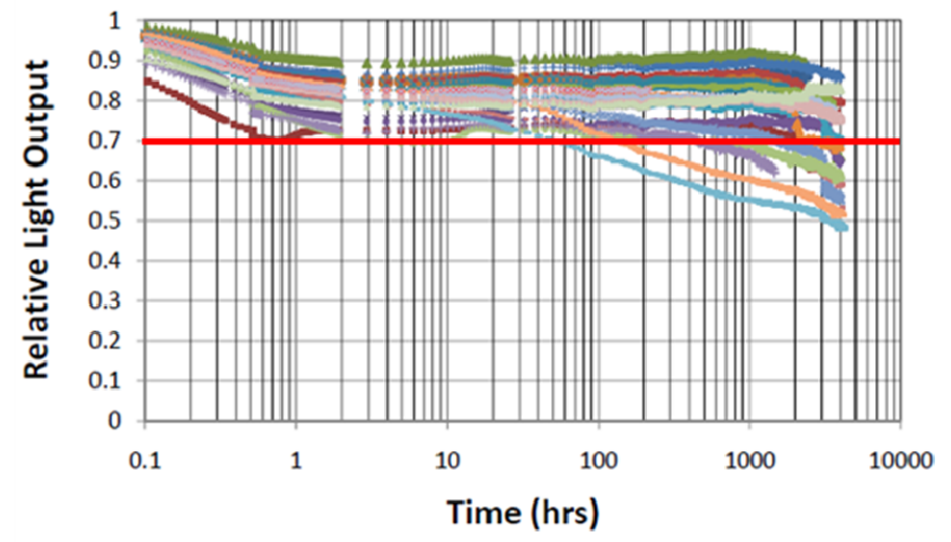

Figure 4. Relative light output over time for 22 LED-based replacement A-19 lamps ${ }^{[11]}$

\subsection{Electrical performance}

The LED lighting system's electrical performance is also important to the system's reliability. The LED driver, which powers the system, also can succumb to high temperatures and shorten the life of the entire system. A Lighting Research Center study showed that the electrolytic capacitor is the weakest component within the driver, and that heat degrades capacitor life. The study showed that driver output current ripple can be used to predict LED driver life, and that driver life decreases exponentially with temperature. ${ }^{[13,14]}$ Overall, any one of the components within an LED lighting system, besides the LED packages themselves, can fail and render the system useless. Therefore, accelerated test methods are needed to predict system failure under realistic operating conditions. The Lighting Research Center and the Alliance for Solid-State Illumination Systems and Technologies (ASSIST) are presently studying the issue of system reliability prediction. Preliminary results investigating acceleration parameters are showing that temperature change and ramp rate likely have good correlation to life, while maximum junction temperature likely has a weak correlation. This study is ongoing.

Dimming and the use of LED replacement lamps on existing triac-style residential dimmers is also a concern for the acceptability of LED lighting. The solid-state lighting industry presently does not have a good definition for dimming. A recent study investigated the dimming performance of commercially available LED replacement lamps and the performance variations among different residential dimmers. Minimum and maximum light output along the dimming range for a variety of residential dimmers and lamps (LED, CFL and incandescent), as well as inrush and repetitive peak currents, were measured. The study found that a lamp's performance with one dimmer could not predict its performance with another dimmer, and that even an incandescent lamp can show a different dimming range from one dimmer to the next. ${ }^{[15,16,17]}$

Some control methods for LED lighting systems are also prone to cause flicker, which may be unacceptable. One study showed that the perception of flicker can be affected by frequency, modulation depth, duty cycle, and waveform shape ${ }^{[18]}$ However, while stroboscopic effects are visible at frequencies as high as $1000 \mathrm{~Hz}$, they are not necessarily unacceptable. ${ }^{[19]}$

\subsection{Ease of purchase}

Cost, availability, product labeling, and warranties will all impact the ultimate acceptance and market success of LED replacement lamps. The retail purchase price of an LED replacement lamp in 2011 often prompts "sticker shock" among consumers, who are accustomed to an incandescent A-lamp costing US\$1 or less, and a CFL costing US\$2-\$5. LED lamps in stores typically range from US\$17 to US\$60, depending on the lamp type. This price must come down; rebates and subsidies can help. The availability of LED lamps also has to be widespread, with lamps for purchase at grocery stores, pharmacies, local hardware stores, and "big box" retailers. Replacement must be easy and can be ensured through long-term availability of the "same" product, one that has the same form factor, appearance, and performance. 
The clarity of product labeling will also play a role. New labeling requirements mandated by the U.S. Federal Trade Commission will go into effect in 2012, meaning that consumers will have to learn a new lighting language. Consumers will be expected to purchase a lamp based on its lumen ratings rather than the number of watts. This will require extensive public education because the number of lumens produced by a traditional 100 -watt incandescent lampspecific knowledge needed to purchase an acceptable alternative CFL or LED lamp - is generally unknown to most people.

Finally, given the reliability issues possible with LED replacement lamps, warranties will be necessary to ensure that consumers can replace a faulty lamp should it fail prematurely. How the warranty is designed and what constitutes replacement under warranty is a more complicated issue to be determined.

\section{IMPLICATIONS OF EISA 2007 AND READINESS OF LED REPLACEMENT LAMPS}

At the present time, there are a number of alternatives available in the market to replace the four categories of incandescent lamps $(100 \mathrm{~W}, 75 \mathrm{~W}, 60 \mathrm{~W}$, and $40 \mathrm{~W})$ to be phased out in the coming years. These include halogen lamps and CFLs for all four categories, and LED lamps for all but the $100 \mathrm{~W}$ category, which should be available by the end of the phase-out plan. As LED lamps become more readily available for residential use and their initial purchase cost reduces, their market share and the number of installations are expected to increase.

Some LED replacement lamps today have the light output, color, and efficacy to meet consumers' needs, but more products will need to target people's desires for the "look and feel" of light, which typically matches that of the incandescent lamp. The retail purchase cost has to come down, ideally to US\$5 or less to make it comparable to CFLs and halogen lamps, because most consumers buy lamps based on the first cost without consideration for total operating costs over time. The reliability in applications needs to be high and live up to the 25,000-hour claim, especially for a lamp with a higher purchase price. Warranties also can help consumer satisfaction should a product fail. Regulation and education will be needed to keep poor-performing products out of the market, which could cause consumers to sour on the whole concept of LED lighting. Finally, purchasing and replacing LED lamps has to be made easy.

\section{ACKNOWLEDGMENTS}

Thank you to the sponsors of the Alliance for Solid-State Illumination Systems and Technologies (ASSIST; www.Irc.rpi.edu/assist) for their sponsorship of LED research programs and projects at the Lighting Research Center. Additional thanks go to Mary Cimo, Daniel Frering, Jean Paul Freyssinier, Russ Leslie, Nick Mangione, Daniel Marcus, Leora Radetsky, and Jennifer Taylor of the Lighting Research Center for their assistance with the SPIE plenary presentation and this manuscript.

\section{REFERENCES}

[1] Green, P., "Light bulb saving time," The New York Times, 25 May 2011, Internet: http://www.nytimes.com/2011/05/26/garden/fearing-the-phase-out-of-incandescent-bulbs.html?_r=1.

[2] O'Donnell, J., and Koch, W., "Some consumers resist 'green' light bulbs," USA Today, 7 February 2011, Internet: http://www.usatoday.com/tech/science/environment/2011-02-07-lightbulbs_N.htm.

[3] Johnson, G., "Stocking up on light ahead of bulb phase-out," TODAY News, 25 August 2011, Internet: http://today.msnbc.msn.com/id/44217803/ns/today-today_news/t/stocking-light-ahead-bulb-phaseout/\#.TmEJf2rebDc.

[4] LEDs Magazine, "US House votes down incandescent bulb-ban bill," 13 July 2011, Internet: $\mathrm{http} / / / \mathrm{www}$. ledsmagazine.com/news/8/7/12.

[5] Rea, M.S., editor, [The IESNA Lighting Handbook: Reference and Application, $9^{\text {th }}$ edition] Illuminating Engineering Society of North America, New York (2000).

[6] U.S. Department of Energy, [U.S. Lighting Market Characterization, Volume 1: National Lighting Inventory and Energy Consumption Estimate] (2002).

[7] U.S. Energy Information Agency, "Electricity consumption by end-use in U.S. households, 2001," Residential Enduse Consumption Survey 2001 data tables, Internet: http://www.eia.gov/emeu/reps/enduse/er01_us_tab1.html. 
[8] [Energy Independence and Security Act of 2007] Public Law 110-140, $110^{\text {th }}$ Congress, December 19, Sec. 321-322 (2007).

[9] OIDA Optoelectronics Industry Development Association, [Light Emitting Diodes (LEDs) for General Illumination: An OIDA Technology Roadmap Update 2002] (2002).

[10] EnergyStar.gov, [ENERGY STAR Qualified LED Light Bulbs, Last Modified 8/30/2011] Internet: http://www.energystar.gov/index.cfm?fuseaction=iledl.display_products_pdf (2011).

[11] Narendran, N., Freyssinier, J.P., "LED: What to look for today and in the future," NALMCO Annual Tradeshow and Convention, October 18, 2010, Cabo San Lucas, Mexico (2010).

[12] U.S. Department of Energy L-Prize, Internet: http://www.lightingprize.org/index.stm (2011).

[13] Han, L., and Narendran, N., "Developing an accelerated life test method for LED drivers," Proc. SPIE 7422, 742209 (2009).

[14]Han, L., and Narendran, N., "An accelerated test method for predicting the useful life of an LED driver," IEEE Trans. Power Elec. 26(8), 2249-2257 (2011).

[15]ASSIST, [ASSIST Technical Note: Dimming LED Integral Lamps] Internet: http://www.lrc.rpi.edu/programs/solidstate/assist/pdf/ASSIST-TechNote-Dimming-LEDIntegralLamps.pdf (2011).

[16]ASSIST, [ASSIST Technical Note: Variations in Household Wall Dimmers for Lighting] Internet: http://www.lrc.rpi.edu/programs/solidstate/assist/pdf/ASSIST-TechNote-DimmingVariationsInHouseholdDimmers.pdf (2011).

[17]ASSIST, [ASSIST Technical Note: Repetitive Peak and Inrush Currents] Internet: http://www.lrc.rpi.edu/programs/solidstate/assist/pdf/ASSIST-TechNote-Dimming-InrushCurrent.pdf (2011).

[18] Bullough, J.D., Sweater Hickcox, K., Klein, T.R., and Narendran, N., "Effects of flicker characteristics from solidstate lighting on detection, acceptability and comfort," Light. Res. Technol. 43(3), 337-348 (2011).

[19] Bullough, J.D., Sweater Hickcox, K., Klein, T.R., Lok, A., and Narendran, N., "Detection and acceptability of stroboscopic effects from flicker," Light. Res. Technol. (In press). 